\title{
906.
}

\section{NOTE ON SCHLAEFLI'S MODULAR EQUATION FOR THE CUBIC TRANSFORMATION; WITH A CORRECTION.}

[From the Messenger of Mathematics, vol. xx. (1891), pp. 59, 60; 120.]

The equation in question, Crelle, t. LXxII. (1870), p. 369, is

$$
S^{4}+T^{4}+8 S T-S^{3} T^{3}=0
$$

where

$$
S=\frac{\sqrt{ } 2}{\sqrt[4]{\left(k k^{\prime}\right)}}, \quad T=\frac{\sqrt{ } 2}{\sqrt[4]{\left(\lambda \lambda^{\prime}\right)}}
$$

which must be of course equivalent to the ordinary modular equation

where

$$
u^{4}-v^{4}+2 u v-2 u^{3} v^{3}=0,
$$

$$
u=\sqrt[4]{k}, \quad v=\sqrt[4]{ } \lambda
$$

the resemblance in form between the two equations, with such different meanings of the $S$ and $T$ in the one case, and the $u$ and $v$ in the other, is very noticeable.

Schlaefli's equation is

$$
\frac{4}{k k^{\prime}}+\frac{4}{\lambda \lambda^{\prime}}+\frac{16}{\left(k k^{\prime} \lambda \lambda^{\prime}\right)^{\frac{2}{2}}}-\frac{8}{\left(k k^{\prime} \lambda \lambda^{\prime}\right)^{\frac{3}{4}}}=0
$$

that is,

$$
k k^{\prime}+\lambda \lambda^{\prime}=2\left(k k^{\prime} \lambda \lambda^{\prime}\right)^{\frac{2}{2}}-4\left(k k^{\prime} \lambda \lambda^{\prime}\right)^{\frac{8}{4}},
$$

or say

$$
k^{2} k^{\prime 2}+\lambda^{2} \lambda^{\prime 2}=4\left(k k^{\prime} \lambda \lambda^{\prime}\right)^{\frac{1}{2}}-18\left(k k^{\prime} \lambda \lambda^{\prime}\right)+16\left(k k^{\prime} \lambda \lambda^{\prime}\right)^{\frac{3}{2}}
$$

To deduce this from the $u v$-modular equation, we have (Jacobi's Fund. Nova, p. 68, Ges. Werke, t. I., p. 124),

$$
\left(1-u^{8}\right)\left(1-v^{8}\right)=\left(1-u^{2} v^{2}\right)^{4}
$$


or, multiplying each side by $u^{8} v^{8}$, and extracting the fourth root, we have

$$
\sqrt{ }\left(k k^{\prime} \lambda \lambda^{\prime}\right)=u^{2} v^{2}\left(1-u^{2} v^{2}\right)=x-x^{2},
$$

if for shortness we write $x=u^{2} v^{2}$.

The equation to be proved thus is

$$
u^{8}\left(1-u^{8}\right)+v^{8}\left(1-v^{8}\right)=4\left(x-x^{2}\right)-18\left(x-x^{2}\right)^{2}+16\left(x-x^{2}\right)^{3} .
$$

But from the foregoing equation

we have

$$
\left(1-u^{8}\right)\left(1-v^{8}\right)=\left(1-u^{2} v^{2}\right)^{4}
$$

and thence

$$
u^{8}+v^{8}=4 u^{2} v^{2}-6 u^{4} v^{4}+4 u^{6} v^{6},=4 x-6 x^{2}+4 x^{3},
$$

$$
u^{16}+v^{16}=\left(4 x-6 x^{2}+4 x^{3}\right)^{2}-2 x^{4} ;
$$

and the equation to be proved thus becomes

$$
\left(4 x-6 x^{2}+4 x^{3}\right)-\left(4 x-6 x^{2}+4 x^{3}\right)^{2}+2 x^{4}=4\left(x-x^{2}\right)-18\left(x-x^{2}\right)^{2}+16\left(x-x^{2}\right)^{3},
$$

which is in fact an identity, each side being

$$
=4 x-22 x^{2}+52 x^{3}-66 x^{4}+48 x^{5}-16 x^{6} .
$$

\section{Correction, p. 120.}

I find that I misquoted Schlaefli's equation, viz. in effect, I took it to be

$$
S_{1}^{4}+T_{1}^{4}+8 S_{1} T_{1}-S_{1}^{3} T_{1}^{3}=0, \text { where } S_{1}=\frac{\sqrt{ } 2}{\sqrt[4]{\left(k k^{\prime}\right)}}, T_{1}=\frac{\sqrt{ } 2}{\sqrt[4]{\left(\lambda \lambda^{\prime}\right)}}:
$$

whereas his equation really is

$$
S^{4}+T^{4}-8 S T+S^{3} T^{3}=0, \text { where } S=2 \sqrt[4]{ }\left(k k^{\prime}\right), \quad T=2 \sqrt[4]{ }\left(\lambda \lambda^{\prime}\right) .
$$

The change is only a change of form, for writing $S_{1}=\frac{2 \sqrt{ } 2}{S}$ and $T_{1}=\frac{2 \sqrt{ } 2}{T}$, the equation in $\left(S_{1}, T_{1}\right)$ is converted into that in $(S, T)$; but it was quite an unnecessary one, and I cannot account for having made it, as the paper in Crelle must have been before me.

C. XIII. 